\title{
Organización que aprende. Caso LATU, Gerencia de Gestión Empresarial
}

\author{
Silva, G. ${ }^{(1)}$, di Candia, C. ${ }^{(1)}$ \\ Contacto: silvaubi@adinet.com.uy \\ ${ }^{(1)}$ Gerencia de Gestión Empresarial - Laboratorio Tecnológico del Uruguay (LATU)
}

\begin{abstract}
Resumen
En 2001, LATU creó un departamento para brindar servicios de consultoría. Para ello, usó el conocimiento institucional y desarrolló las condiciones propicias para la creación de conocimiento interno. Dentro de las herramientas de Gestión del Conocimiento utilizadas internamente se destacan: Transferencia de personal (rotación del personal y generación de redundancia), Transferencia de experiencias ejemplares (transferencia en serie y transferencia cercana) y Comunidades de práctica (grupos de mejora de procesos)

Como consecuencia de cambios organizacionales en 2006, dicho servicio, junto con otros departamentos, pasó a formar parte de la Gerencia Gestión Empresarial. En la misma se complementaron las herramientas de transferencia: Transferencia lejana, Transferencia estratégica y Transferencia experta

Como parte de la transferencia de conocimiento a los clientes externos, el compromiso de la Gerencia es la utilización del conocimiento como recurso estratégico induciendo al uso de las herramientas desarrolladas realizando más de cien proyectos en Uruguay, El Salvador, República Dominicana, México, Perú., efectivizando la transferencia de conocimiento al cliente final.
\end{abstract}
Abstract
In 2001, LATU set up a department to provide consulting services. For this, used the institutional knowledge and developed the condi- tions for the creation of internal knowledge.
Within the Knowledge Management tools used internally highlights:
Transfer of personnel (Rotation of staff and Generation Redundancy ),
Transfer experiences copies (Serial Transfer and Transfer nearby) and
Communities of practice (Groups Process Improvement)
As a result of organizational changes in 2006, the service, along with other departments, became part of the Business Administration Consultancy Management. In the same way were complemented transfer tools: Remote Transfer, Strategic Transfer andTransfer expert
As part of the knowledge transfer (consultancy) to external customers, the commitment of the management is the use of knowledge as a strategic resource inducing the use of the tools developed in more than a hundred projects in Uruguay, EI Salvador, Dominican Republic, Mexico and Peru, giving effect the knowledge transfer to the final customer.

\section{Objetivo}

$\mathrm{I}$ dentificar la transferencia de conocimiento que tiene lugar en la Gerencia de Gestión Empresarial del LATU. Identificar la transferencia de conocimiento a los clientes a través del proceso de consultoría. Determinar la relación existente entre ambos tipos de transferencia (interna y externa).

\section{Introducción}

La gestión del conocimiento implica crear las condiciones que permitan a las personas producir, aplicar y/o transferir un conocimiento válido para la organización y potenciar su desarrollo personal, capturar la pericia colectiva de la organización y ponerla a disposición a quien lo necesite, permitiendo la innovación y aprovechando el trabajo intelectual acumulado.

La gestión del conocimiento "es la capacidad de una organización para crear nuevo conocimiento, diseminarlo a través de la organización y expresarlo en productos, servicios y sistemas" (Nonaka \& Takeuchi, 1995).

El Laboratorio Tecnológico del Uruguay - LATU es un instituto creado en el año 1965, fruto del esfuerzo conjunto de los sectores oficiales y privados del Uruguay, con el propósito de brindar servicios de valor en tecnología y gestión que impulsen el desarrollo de la comunidad. El objetivo del LATU es promover la competitividad empresarial mediante el desarrollo de soluciones tecnológicas y transferencia de conocimiento.
En el año 2001, elLATU creó un departamento para brindar servicios de consultoría en gestión. Para ello, usó el conocimiento institucional y desarrolló las condiciones propicias para la creación de conocimiento interno. Como consecuencia de cambios organizacionales en el año 2006, dicho servicio paso a formar parte de la Gerencia de Gestión Empresarial cuya misión es: "Generar y transferir conocimiento, gestionar proyectos, unidades productivas y de apoyo: a través de la investigación, articulación e innovación en herramientas de gestión de organizaciones con el objetivo, eficaz, sostenible y socialmente responsable de nuestros clientes".

La gestión del conocimiento en la Gerencia de Gestión Empresarial se concibe como una actividad transversal de apoyo a todos los procesos que se llevan a cabo en la misma; con el objeto de mejorar su gestión y como proceso específico que se suma a los existentes. Este proceso engloba cuatro dimensiones principales, a saber la creación del conocimiento, su codificación, transferencia del mismo para desembocar en la aplicación y reutilización.

\section{Marco teórico}

El modelo de conversión del conocimiento de Nonaka y Takeuchi, 1995, se focaliza en la espiral de conocimiento la cual explica la transformación de conocimiento tácito en explícito y viceversa como la base para la innovación y el aprendizaje tanto a nivel individual, grupal como organizacional. Este modelo es representado a través de dos espirales de contenido epistemológico y ontológico. Es un proceso de 
interacción entre conocimiento tácito y explícito que tiene naturaleza dinámica y continua.

El modelo se fundamenta en el supuesto crítico que el conocimiento humano se crea y expande a través de la interacción social de conocimiento tácito y conocimiento explícito. Dicha conversión es un proceso social entre individuos y no está confinada al interior de un individuo.

El modelo de conversión del conocimiento comprende cuatro subprocesos de manera que cada modo de conversión del conocimiento desemboca en un nuevo conocimiento. Si el conocimiento tácito producido en la socialización no es convertido en explícito a través de la exteriorización, difícilmente el nuevo conocimiento podrá desembocar en algún tipo de innovación. Del mismo modo, si el conocimiento explícito generado en la combinación no puede ser interiorizado por los miembros de la organización, una buena parte del nuevo conocimiento se habrá perdido.

Figura 1

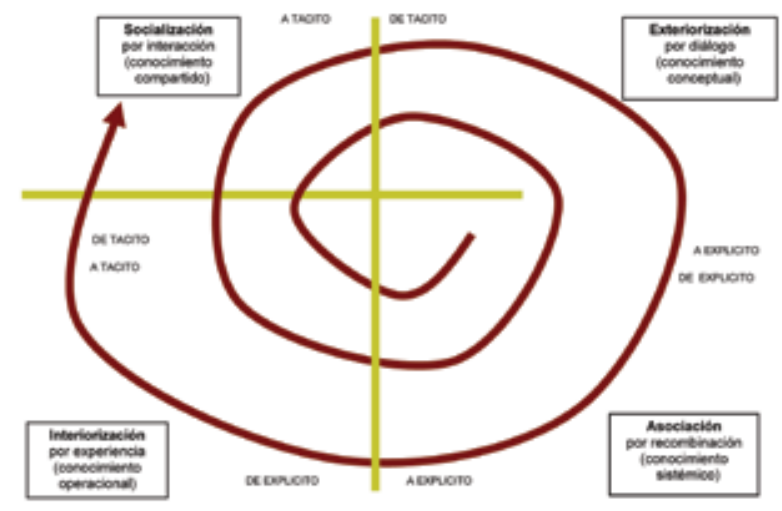

\section{ESPIRAL DEL CONOCIMIENTO}

La creación de conocimiento organizacional, por lo tanto, debe ser entendida como un proceso que organizacionalmente amplifica el conocimiento creado por los individuos y lo cristaliza como una parte de la red de conocimiento de la organización.

Figura 2

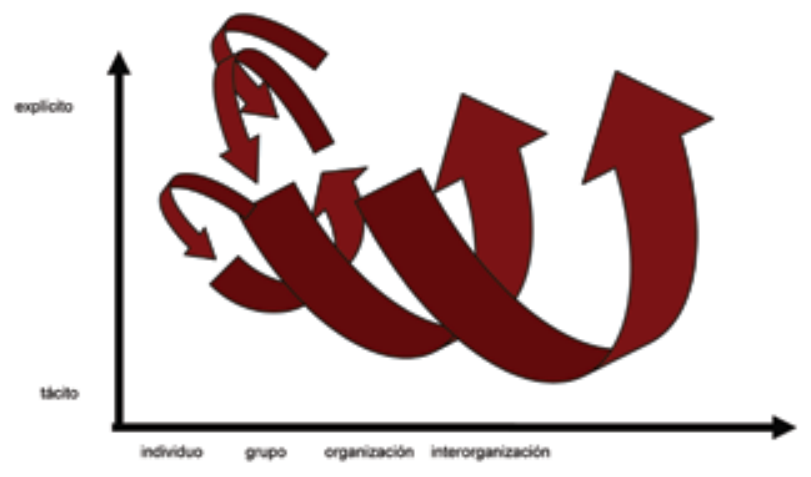

Este modelo de conversión del conocimiento contextualiza el proceso de gestión del conocimiento que engloba cuatro dimensiones principales: la creación del conocimiento, codificación del mismo, su transferencia para desembocar en su aplicación y reutilización.

Figura 3

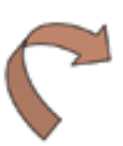

\section{CREACIÓN}

APLICACIÓN Y

REUTILIZACIÓN

CODIFICACION

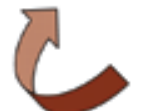

TRANSFERENCIA

\section{Proceso de gestión del conocimiento}

El proceso de creación de conocimiento se desencadena a partir de los datos, la información y el conocimiento. Una organización orientada al conocimiento almacena los datos en forma descentralizada haciéndolos disponibles a todos los integrantes de la misma ya sea en las carpetas informáticas como en los archivadores físicos. A su se promueve la creación conciente e intencionada de nuevo conocimiento. Este último se codifica y documenta de forma que resulte accesible a todos quienes lo requieran, haciéndolo explícito, transportable y fácil de entender.

La transferencia de conocimiento acontece en forma natural en las organizaciones. La plena transferencia de conocimiento engloba dos momentos: la presentación del conocimiento a un posible receptor y la asimilación por parte de la persona o grupo receptor. La transferencia efectiva deberá conducir a mejoras en las actividades, creación de valor, cambios positivos en los comportamientos, desarrollo de nuevas ideas, entre otros.

\section{Gestión del conocimiento en la Gerencia de Gestión Empresarial del LATU}

\section{Condiciones de creación del conocimiento}

La creación de conocimiento es el desarrollo de nuevo conocimiento, know-how e innovaciones que no tenían existencia previa en la organización.

El papel que la Gerencia juega dentro del proceso de creación de conocimiento organizacional es el de proveer el contexto adecuado que facilite las actividades de grupo y que, asimismo, facilite la creación y la acumulación de conocimiento en el nivel individual. Es así que dentro de la Gerencia de gestión empresarial se dan las condiciones para la creación del conocimiento: propósito, autonomía, fluctuación, caos y redundancia.

El propósito es la aspiración de una organización a la consecución de sus metas a través de la generación de una estrategia. La misión de la Gerencia refleja la esencia de la estrategia de la creación de conocimiento como la capacidad organizacional necesaria para adquirir, crear, acumular y explotar el conocimiento.

Uno de los instrumentos más eficaces relacionados con la autonomía son los grupos autogestionados. Dentro de la Gerencia de gestión empresarial, los integrantes son los responsables de la planificación de las actividades de la actividades de los servicios que brindan, el seguimiento de los tiempos y objetivos definidos, el cumplimiento de dichos objetivos, el resultado alcanzado y la evaluación final. Por ejemplo los consultores coordinan y conducen como referentes técnicos el diseño y ejecución de los proyectos y asesoramientos, con foco en la transferencia de conocimiento, investigación, innovación y desarrollo de productos y/o sistemas de gestión y la transferencia de herramientas de gestión y tecnologías validadas dirigidas a los distintos sectores productivos, para contribuir en la ampliación y mantenimiento actualizado de la oferta de productos y servicios de la Gerencia y a la promoción de los cambios empresariales hacia la innovación, consolidación, eficiencia, y competitividad de las empresas/productores uruguayos. Esta autonomía permite que los integrantes de la Gerencia actúen de forma independiente, ya que todos manejan la misma información, incrementando así las oportunidades de acceder y utilizar el conocimiento que está en las personas y las probabilidades de encontrar información valiosa, acceder a oportunidades inesperadas motivando el compromiso y la creación.

El ser el LATU un organismo paraestatal, trae aparejado que los cambios de gobierno provoquen cambios dentro de la estructura organizacional de LATU. La Gerencia de Gestión Empresarial se ha visto afectada por estos cambios, lo que se puede apreciar en los cambios de estructura que ha experimentando en el correr de los años. Este 
ambiente de fluctuación, haciendo referencia a los cambios o rupturas que puede sufrir la organización, y caos, efectos que dichas fluctuaciones generan en la organización, estimula la interacción entre la organización y su medio. La interrupción de las rutinas fomenta el des - aprendizaje y la creación de conocimiento. La generación y desarrollo de nuevos proyectos dentro de la Gerencia, propiciando la innovación y creatividad es la evidencia que estos procesos se están llevando a cabo.

Dentro de la Gerencia de gestión empresarial existen dos departamentos orientados uno de ellos a la gestión pública y el otro a la gestión privada. Dentro de las actividades de cada departamento se encuentra la gestión del contacto con el cliente, la definición del proyecto, la generación del contrato o concreción de la venta, la transferencia de conocimiento y la evaluación del proyecto. Si bien las actividades se llevan a cabo en forma independiente existe una interacción e intercambio permanente entre ambos departamentos. Claramente se encuentra redundancia, el uso deliberado de información sobrepuesta que cumple la función de promover el intercambio de conocimiento tácito ayudando a hacer efectivo el proceso de interiorización

La existencia de grupos multidisciplinarios, la rotación de consultores entre los equipos de consultoría y el hecho que la información esté disponible por búsqueda proactiva o a solicitud de los clientes implica diversidad. Es decir que todas las personas de la Gerencia cuentan con acceso rápido a la máxima cantidad de información posible y con la mínima cantidad de pasos, de manera de poder responder de la manera más rápida a las fluctuaciones del ambiente lo que permite lograr un equilibrio entre el orden (integración interna) y el caos (cambios del entorno no totalmente predecibles).

\begin{tabular}{|l|l|}
\hline MODELO & MIDDLE-UP-DOWN \\
\hline $\begin{array}{l}\text { Agente de creación de } \\
\text { conocimiento }\end{array}$ & $\begin{array}{l}\text { Equipo (con los mandos medios como } \\
\text { ingenieros del conocimiento) }\end{array}$ \\
\hline Papel de la dirección & Catalizador \\
\hline Papel de los mandos intermedios & Jefe de equipo \\
\hline Conocimiento acumulado & Explícito y Tácito \\
\hline Conversión del conocimiento & $\begin{array}{l}\text { Espiral de conversión: socialización, } \\
\text { interiorización, asociación y la }\end{array}$ \\
\hline Almacén de conocimiento & Base de conocimiento organizacional \\
\hline Organización & Jerárquica y equipos específicos \\
\hline Comunicación & Diálogo, uso de metáforas y analogías \\
\hline Tolerancia hacia la ambigüedad & Crea y amplía la fluctuación y el caos \\
\hline Debilidades & $\begin{array}{l}\text { Coste de la redundancia y capital } \\
\text { humano }\end{array}$ \\
\hline
\end{tabular}

La Gerencia de Gestión Empresarial se ubica en el modelo middleup-down para la creación del conocimiento.

Herramientas de gestión del conocimiento

Dentro de las herramientas de Gestión del Conocimiento utilizadas por la Gerencia de Gestión Empresarial se destacan:

1. Transferencia de personal

a. Rotación de personal

Dentro de la Gerencia se realizan entrenamientos de consultores junior a la vez que se realiza la rotación de los equipos consultores, es decir que para cada consultoría el equipo consultor varía su composición. Esto tiene como objetivo el socializar un conocimiento tácito desde los más experimentados, "maestro" o "experto", mediante la observación, la imitación y la práctica. Asimismo, compartir experiencias de manera de mejorar continuamente el proceso abarcando en forma completa el espiral del conocimiento.

b. Generación de redundancia.

La redundancia se da por superposición y por competencia. En el caso de la superposición, existen dos departamentos que trabajan juntos gestionando proyectos de consultoría cuyo objetivo es compartir conocimiento tácito mediante el aprendizaje por "entrometimiento". Para el caso de la competencia, diferentes equipos (mas de un equipo auditor y el equipo consultor) en un mismo proyecto para desarrollar diferentes enfoques y discutir ventajas y desventajas de cada uno, compartiendo conocimiento tácito.

2. Transferencia de experiencias de ejemplares

Puede definirse a la práctica ejemplar como aquélla que ha dado buenos resultados en alguna situación y podría ser adaptada a la situación actual de que se trate.

a. Transferencia en serie

La transferencia en serie existe, dentro de la Gerencia, tanto a nivel individual dentro del equipo consultor como por la aplicación de las reuniones de coordinación.

Dentro del equipo consultor porque el mismo repite tareas en nuevos contextos, reutilizando el conocimiento de cada práctica, evitando de este modo la reiteración de errores e incrementando la eficiencia y calidad de su trabajo.

De esta manera los integrantes del equipo logran que su conocimiento tácito se convierta en explícito, tanto para sí mismos como para los otros miembros del equipo. A su vez la existencia de reuniones de coordinación promueve la transferencia permanente del conocimiento.

\section{b. Transferencia cercana}

Es la transferencia de un equipo que ha aprendido algo, a otro que realiza tareas semejantes en contextos similares, pero en otro lugar, difundiendo de esta manera mejoras a los procedimientos más o menos rutinarios y conocidos por ambos. La realización de auditorías internas por parte de otros consultores permite que el aprendizaje en otra consultoría / auditoria en un contexto diferente pero similar se transfiera; lo mismo ocurre con la rotación de los equipos consultores para las diferentes consultorías.

La gerencia planifica a lo largo del año la realización de lecciones aprendidas y talleres de transferencia, reuniones de todos los integrantes de la misma para compartir conocimiento y experiencias, teniendo estos encuentros un efecto reforzador sobre la actividad y principalmente como fuente de garantía de la calidad de la persona que generó el nuevo conocimiento.

\section{c. Transferencia lejana}

La formación de equipos multidisciplinarios para el diseño de nuevos servicios de la Gerencia de Gestión Empresarial, implica el traslado del conocimiento tácito de un equipo a otro en tareas no rutinarias, en contextos diferentes. En este caso, los intercambios son recíprocos ya que ambos equipos aprenden. Las personas transportan el conocimiento tácito a través de la organización y el conocimiento emerge cuando es estimulado por la situación de demanda.

d. Transferencia estratégica

Incluye la transmisión de conocimiento complejo (tanto tácito como explícito) de un equipo que se encuentra distante de otro (en el espacio y el tiempo), que afecta a buena parte del sistema y aspira a evitar errores muy costosos en momentos transcendentes. Su diferencia respecto a la transferencia lejana es que se trata de proyectos muy esporádicos o únicos con alto impacto en toda la organización.

Son quienes cumplen funciones de nivel superior quienes identifican los temas acerca de los cuales la organización debería buscar conocimiento y las oportunidades para hacerlo. Ese conocimiento es interno, es decir, debe estar en la memoria colectiva de la organización.

Los integrantes de la Gerencia de Gestión Empresarial participan activamente de proyectos organizacionales; a saber: proyecto de fortalecimiento de la comunicación interna, proyecto de seguridad de la información, proyecto de evaluación de desempeño, proyecto plan de carrera, proyecto de fortalecimiento del modelo de mejora continua, proyecto de gestión del conocimiento, otros en etapa de diseño.

\section{e. Transferencia experta}

La Gerencia de Gestión Empresarial utiliza expertos técnicos de la organización cuando un equipo se enfrenta a un asunto técnico más allá del alcance de sus conocimientos; buscando de esta manera la pericia de otras personas dentro de la organización. Tal es el caso de 
la colaboración de expertos en el tema lácteos, bebidas fermentadas, alimentos en general, informática, seguridad, entre otros, en la realización de auditorías internas dentro del marco de las consultorías. En estos casos el equipo receptor realiza una tarea diferente a la fuente, pero en contexto similar.

3. Comunidades de práctica

Una Comunidad de Práctica es un grupo de personas que comparten una preocupación, un conjunto de problemas o un interés común acerca de un tema, y que profundizan su conocimiento y pericia en esta área a través de una interacción continuada.

Los compañeros de trabajo en una organización, con ciertos conocimientos complementarios y objetivos y prácticas laborales en común, pueden conformar grupos autoorganizados espontáneamente. Algunos de estos grupos, llegan a formalizar su constitución, convirtiéndose en verdaderas comunidades de práctica.

El LATU, en el año 1999, creo los Grupos de Mejora de aplicación a todos los procesos de la organización. Estos grupos se generaron con una identidad definida y por un interés compartido que fue la mejora de los procesos existentes en al organización. El hecho de ser un miembro implicaba un compromiso con ese campo de actividad y esa competencia lo distinguía de otras personas, aunque, esta pericia no fuera reconocida fuera de esa comunidad. Estas comunidades, se crearon, en el sentido de compartir información, ayudarse mutuamente, mantener discusiones y actividades conjuntas. Desarrollaron un repertorio de herramientas y experiencias, así como enfrentaron problemas prácticos en común atendiendo a dificultades recurrentes de su praxis, lo que implicó el uso de una cantidad significativa de tiempo e interacción.

La Gerencia de Gestión Empresarial adoptó esta práctica no solo para si sino también para aplicarla en las organizaciones a las cuales les estaba brindando servicio de consultoría. Los grupos de mejora conciben el aprendizaje como un hecho colectivo, es un proceso continuo, tienen la característica de ser informales y autoorganizadas, pero estructuradas, a diferencia de los equipos de proyecto, no tienen una duración preestablecida y por lo general sobreviven los cambios. En los grupos de mejora se puede contactar con otros miembros de la organización sin seguir los caminos y requisitos formales. Los grupos de mejora operan con un coordinador o moderador que tiene como característica dinamizar el enriquecimiento mutuo y el intercambio identificando temas importantes a tratar, planificar las actividades del grupo, conectar a sus miembros, gestionar la frontera entre el grupo y la organización formal, ayudar a construir conocimiento, mejores prácticas, herramientas, memoria, evaluar las contribuciones de sus miembros y la salud del propio grupo.

\section{Transferencia externa}

Como los grupos de mejora resultaron una herramienta positiva en la transferencia de conocimiento en LATU, la Gerencia de Gestión Empresarial induce al uso de los mismos en las consultorías que desarrolla.

El equipo consultor propone a las organizaciones, como herramienta de mejora, la identificación y formación de estas comunidades.

Como parte de la transferencia externa, hay que tener en cuenta que existen condiciones que dificultan y hasta impiden que las organizaciones aprendan.

\begin{tabular}{|l|l|}
\hline FACTORES INHIBIDORES & POSIBLES SOLUCIONES \\
\hline Falta de confianza & $\begin{array}{l}\text { Construir relaciones y encuentros cara } \\
\text { a cara }\end{array}$ \\
\hline $\begin{array}{l}\text { Diferentes culturas, terminología } \\
\text { y marco de referencia }\end{array}$ & $\begin{array}{l}\text { Crear lugares comunes a través de } \\
\text { la formación, trabajo en equipo y la } \\
\text { rotación de puestos }\end{array}$ \\
\hline $\begin{array}{l}\text { Falta de tiempo y lugares de } \\
\text { encuentro }\end{array}$ & $\begin{array}{l}\text { Instalar tiempos y lugares para la } \\
\text { transferencia de conocimiento }\end{array}$ \\
\hline
\end{tabular}

\begin{tabular}{|l|l|}
\hline $\begin{array}{l}\text { Falta de capacidad de absorción } \\
\text { en los destinatarios }\end{array}$ & Proporcionar tiempo para el aprendizaje \\
\hline $\begin{array}{l}\text { Creencia que el conocimiento es } \\
\text { asunto de determinados grupos } \\
\text { de la organización }\end{array}$ & $\begin{array}{l}\text { Fomentar un acercamiento no jerárquico } \\
\text { al conocimiento }\end{array}$ \\
\hline $\begin{array}{l}\text { Intolerancia frente a los errores } \\
\text { o la necesidad de ayuda }\end{array}$ & $\begin{array}{l}\text { Aceptar y recompensar los errores } \\
\text { creativos y la colaboración }\end{array}$ \\
\hline
\end{tabular}

En el marco de la consultoría, identificar estos factores inhibidores para poder neutralizarlos en un desafío al cual los integrantes de la Gerencia se enfrentan a diario.

Como parte de la transferencia de conocimiento a los clientes externos la Gerencia de Gestión Empresarial ha definido, para algunos de los departamentos que la integran, la consultoría excelente, en la búsqueda de sistematizar los factores de éxito en las consultorías y la forma de medición de los mismos. Con esto se pretende medir la efectividad de la transferencia externa en las empresas a las cuales se les brindo el servicio. Para ello a definido una serie de factores a ser cumplidos por los equipos consultores. Estos son: ideas innovadoras, cumplimiento de tiempos (tiempo total y carga horaria), adecuación de la norma a la organización, trabajo en equipo, satisfacción del cliente, otras ventas, impacto de la consultoría en la gestión del cliente, certificación, publicaciones. Para cada uno de ellos se han definido indicadores

\section{Conclusiones}

$\mathrm{E}$ el compromiso de la Gerencia la utilización del conocimiento como recurso estratégico induciendo al uso de las herramientas desarrolladas efectivizando la transferencia de conocimiento al cliente final.

Mantener un equipo de profesionales competentes que contribuyan al cumplimento de la misión definida para la Gerencia de Gestión Empresarial, implica necesariamente gestionar adecuadamente los conocimientos existentes entre sus integrantes. El posicionamiento futuro de los servicios que se brindan dependerá del mantenimiento de las herramientas mencionadas en el presente caso y el desarrollo de nuevas metodologías de optimización de la gestión del conocimiento que actualmente se realiza.

\section{Referencias}

Argyris, C. Sobre el aprendizaje organizacional, Mexico : Oxford University Press, 2001.

CIDEC;Centro de Investigación y Documentación sobre problemas de la Economía, el Empleo y las Cualificaciones Profesionales. 2000 Gestión de Conocimiento y Capital Intelectual. En: Cuadernos de Trabajo. 31. Donostia, San Sebastián

CIDEC;Centro de Investigación y Documentación sobre problemas de la Economía, el Empleo y las Cualificaciones Profesionales. 2001. Construyendo la cultura del conocimiento en las personas y las organizaciones. En: Cuadernos de Trabajo. 34. Donostia, San Sebastián

Davenport, T. H.; Prusak, L. Conocimiento en Acción: Cómo las organizaciones manejan lo que saben. Buenos Aires : Pearson Education, 2001

Dixon, N. M. El Conocimiento Común : Cómo prosperan las compañías que comparten lo que saben. México: Oxford University Press, 2001

Nonaka, I.; Takeuchi, H. La Organización creadora del conocimiento. México: Oxford University Press, 1999

O'dell, C.; Jackson Grayson, C.; Essaides, N. Si tan sólo supiéramos lo que sabemos , España, 2001

Senge, P. La quinta disciplina : cómo impulsar el aprendizaje en la organización inteligente. México: Granica, 1998 